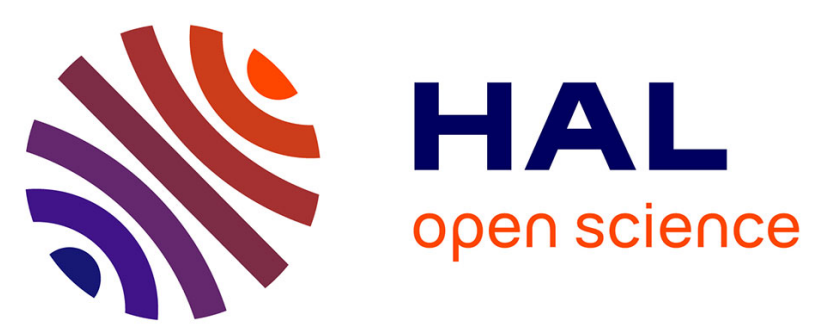

\title{
Free fatty acid release from vegetable and bovine milk fat-based infant formulas and human milk during two-phase in vitro digestion
}

Jeske Hageman, Jaap Keijer, Trine Kastrup Dalsgaard, Lara Zeper, Frédéric Carrière, Anouk Feitsma, Arie Nieuwenhuizen

\section{To cite this version:}

Jeske Hageman, Jaap Keijer, Trine Kastrup Dalsgaard, Lara Zeper, Frédéric Carrière, et al.. Free fatty acid release from vegetable and bovine milk fat-based infant formulas and human milk during two-phase in vitro digestion. Food and Function, 2019, 10 (4), pp.2102-2113. 10.1039/c8fo01940a . hal-02326910

\section{HAL Id: hal-02326910 https://hal.science/hal-02326910}

Submitted on 16 Nov 2020

HAL is a multi-disciplinary open access archive for the deposit and dissemination of scientific research documents, whether they are published or not. The documents may come from teaching and research institutions in France or abroad, or from public or private research centers.
L'archive ouverte pluridisciplinaire HAL, est destinée au dépôt et à la diffusion de documents scientifiques de niveau recherche, publiés ou non, émanant des établissements d'enseignement et de recherche français ou étrangers, des laboratoires publics ou privés. 
2 Free fatty acid release from vegetable and bovine milk fat-based infant formulas and human milk during two-phase in vitro digestion

4 Jeske HJ Hageman ${ }^{1,2}$, Jaap Keijer ${ }^{1}$, Trine Kastrup Dalsgaard ${ }^{3}$, Lara Zeper ${ }^{1}$, Frédéric Carrière ${ }^{4}$, 5 Anouk L Feitsma², Arie G Nieuwenhuizen ${ }^{1}$

1. Human and Animal Physiology, Wageningen University, de Elst 1, 6708 WD Wageningen, the Netherlands

2. FrieslandCampina, Stationsplein 1, 3818 LE Amersfoort, the Netherlands,

3. Department of Food Science, Aarhus University, Blichers Allé 20, DK-8830 Tjele Aarhus, Denmark 
Background: Bovine milk fat is increasingly used in infant formula (IF). The triacylglycerol (TAG) structure of bovine milk fat might be beneficial for digestion and absorption. We investigated the release of fatty acids (FAs) of IF containing different fat blends and compared this to human milk.

Methods: Fresh human milk was sampled and two IFs were produced; one containing $100 \%$ vegetable fat (IF1) and one with $67 \%$ bovine milk fat and $33 \%$ vegetable fat (IF2). Using a static in vitro infant digestion model, consisting of a gastric and duodenal phase, the time dependent release of individual free fatty acids (FFA) was studied, analysed using GC-MS, and residual TAG levels were determined by GC-FID.

Results: Human milk and the IFs showed comparable total FA release. In the gastric phase, 5$10 \%$ of lipolysis occurred, and mainly short (SCFA)- and medium chain fatty acids (MCFA) were released. In the duodenal phase, lipolysis proceeded with release of SCFA but was marked by a fast release of long-chain fatty acids (LCFA). The digestion of the IFs resulted in different FFA profiles in the course and at the end of digestion. IF2 gave more SCFA and MCFA release, which reflects the FA composition of bovine milk.

Conclusion: The addition of bovine milk fat to IF resulted in a total FA release comparable to an IF with only vegetable fat and human milk. However, it did lead to a different timedependent release of individual FAs, which might result in differences in absorption and other health effects in vivo. 
Introduction

Human milk is the preferred nutrition for infants ${ }^{1}$ ), and it is therefore recognized as the golden standard for infant feeding. Fat is an important nutrient in human milk, delivering about $50 \%$ of the energy to an infant. ${ }^{2}$ Furthermore, it also delivers essential fatty acids (FAs), fat-soluble vitamins and other components like cholesterol. ${ }^{3}$ Human milk fat is composed for $98 \%$ of triacylglycerols (TAGs), formed by the esterification of fatty acids (FAs) at the three stereospecific positions (sn-1, sn-2 and sn-3) of the glycerol backbone.

Digestion of TAGs starts in the stomach by the action of gastric lipase and is completed in the small intestine by pancreatic lipase. Gastric lipase can potentially hydrolyse all three ester bonds of TAGs but shows a stereo-preference for the sn-3 position of TAGs. Since in milk fat the shorter FAs are placed here, this leads to the preferential release of the shorter FAs by gastric lipase. ${ }^{4-6}$ Pancreatic lipase shows regioselectivity for the hydrolysis of the ester bonds at the sn-1 and sn-3 positions, and seems to prefer medium-chain fatty acids (MCFA; C6:0C12:0) over long-chain fatty acids (LCFA; >C12:0). ${ }^{7}$ Therefore, hydrolysis of TAGs by pancreatic lipase results in two free fatty acids (FFA) and a mono-acylglycerol (MAG) with a FA esterified at the sn-2 position. Although the conversion of TAGs into FFA and MAG is sufficient to ensure full intestinal absorption of fat, MAG can be further cleaved to some extent by other enzymes showing high activity on MAG, namely bile salt-stimulated lipase $(\mathrm{BSSL})^{8}$ and pancreatic lipase-related protein $2 .{ }^{9-11}$ Short-chain fatty acids (SCFA; C4:0-C5:0) and MCFA can directly be absorbed in the stomach up to C12 [REF] and by enterocytes, whereas LCFA, and MAGs require the presence of bile salts and incorporation into mixed micelles. These micelles can be transported over the mucosal barrier into the enterocytes. 
Fat digestion and absorption in adults is highly efficient, with $95-97 \%$ of the ingested lipids being hydrolysed and absorbed. ${ }^{3}$ In infants, fat absorption is less efficient. Studies investigating FA excretion in stool samples show that not all lipids are absorbed in infants; in term infants about $10 \%$ of the consumed fat is not absorbed. ${ }^{12}$ This amount of non-absorbed FAs is found to be higher in formula fed infants compared to breast-fed infants. ${ }^{13}$ The fat absorption seems to decrease with increasing FA chain length and increases with the number of double bonds (unsaturated FA). ${ }^{3}$

Human milk fat has a specific TAG structure with most of the palmitic acid, about $70-88 \%$, attached at the sn-2 position ${ }^{14-17}$, whereas unsaturated FA are predominantly at the sn-1 and sn-3 positions. ${ }^{14,15}$ There are several hypotheses why this might be beneficial for an infant. ${ }^{18}$ One of the explanations is that unesterified palmitic acid, like other long-chain saturated fatty acids (LCSFA), is able to form indigestible complexes with calcium in the lumen, called soap formation ${ }^{19,20}$. These calcium soaps are not absorbed and are excreted in faeces. ${ }^{19}$ With palmitic acid at the sn-2 position of the glycerol backbone, and thus not at the sn-1 and sn-3 positions, both the MAG as well as the calcium will be absorbed, resulting in a higher bioavailability of FAs and calcium and protection against stool hardening.

Sometimes human milk is not available, for whatever reason, and infant formula (IF) is used to feed a baby. The fat blends that are used for IF are tailored to the fatty acid composition of human milk, with C16:0 (palmitic acid) and C18:1 (oleic acid) being the most frequently occurring FAs. Nowadays, IFs are mostly based on vegetable fats derived from palm (kernel/olein) oil, sunflower oil, coconut oil, rapeseed oil and safflower oil. ${ }^{21}$ Bovine milk fat, a rich source of palmitic acid, is also used, with increasing popularity. ${ }^{22}$ Whereas palm oil or bovine milk fat based formulas can be designed to have a comparable FA composition, the 
FA distribution on the TAGs differs. In bovine milk fat a higher percentage of palmitic acid is positioned at the sn-2 position of the glycerol backbone, compared to a representative fat blend containing palm oil (40-45\% vs $10-20 \%$ respectively). ${ }^{14,23}$ In most of the vegetable fat blends used in IF the LCSFA are positioned at the sn-1 and sn-3 positions. ${ }^{16,23}$ In bovine milk fat, SCFA, MCFA, unsaturated fatty acids (UFA) and some LCSFA are positioned at sn-1 and sn-3. ${ }^{17}$ The positioning of FA in bovine milk fat thus resembles human milk TAG to a higher degree than a vegetable fat blend containing palm oil. Since bovine milk fat contains low levels of linoleic acid, addition of vegetable fat is needed to reach the required amount of linoleic acid. ${ }^{24}$ Therefore, a maximum of $67 \%$ bovine milk fat can be used in IF. When bovine milk fat is used as a source of palmitic acid, palm oil does not need to be added to reach similar levels of palmitic acid as present in human milk. ${ }^{24}$

Since gastric lipase is known to have an apparent preference for shorter FAs, due to its sn-3 stereo-specificity, and pancreatic lipase for unsaturated FAs, the usage of bovine milk fat compared to palm oil may result in differences in lipolysis, which may affect lipid availability to infants. Therefore, the aim of this study was to investigate the release of fatty acids of IF containing either a vegetable fat blend containing palm oil or a mixture of bovine milk fat and vegetable fat and to compare this to human milk. This was performed using a static twophase in vitro digestion model, mimicking both the gastric and the small intestinal physiological conditions as occurring in an infant. Two different infant formulas and four human milk samples were used. The release of different FAs, ranging from C4:0 to C18:3, was analysed in both the gastric and the intestinal phase, and was compared for the IFs and human milk samples. In addition, the residual TAG concentrations of human milk and the different IFs were determined. 


\section{Products}

Two IF base powders containing different fat blends were provided by FrieslandCampina. IF1 consisted of a mixture of vegetable fat (palm oil, palm kernel oil, rapeseed oil and sunflower sunflower oil and coconut oil). The IF products contained $30 \%$ fat (dry weight) and, besides

In vitro lipolysis experiments

To simulate the digestive system of an infant, a two-phase static in vitro digestion model, 132 including a gastric and duodenal phase, was used. ${ }^{25,26}$ The IFs or human milk, (40 ml), were 
put in a temperature-controlled reaction vessel, kept at $37^{\circ} \mathrm{C}$. The products were mechanically stirred and the $\mathrm{pH}$ was adjusted to 5.5 by addition of $\mathrm{HCl}$. To simulate the gastric phase of digestion at half gastric emptying, IFs or human milk $(40 \mathrm{~mL})$ were mixed with simulated gastric fluid (SGF; $8.0 \mathrm{~mL}$ ) at a 5 to 1 volume ratio [REF]. SGF was prepared by dissolving rabbit gastric extract (RGE; CNRS, Marseille, France) at $1.8 \mathrm{mg} / \mathrm{mL}$ in $10 \mathrm{mM}$ MES buffer, $150 \mathrm{mM} \mathrm{NaCl}$, pH 6.0. RGE contains rabbit gastric lipase and was chosen because of similar properties to human gastric lipase, like regio- and stereo preference. ${ }^{27}$ The lipase activity of the RGE powder was $68 \mathrm{U} / \mathrm{mg}$, using tributyrin as substrate, which corresponds to $57 \mu \mathrm{g} / \mathrm{mg}$. A concentration of $1.8 \mathrm{mg} / \mathrm{mL} \mathrm{RGE} \mathrm{in} \mathrm{SGF} \mathrm{allowed} \mathrm{reaching} \mathrm{a} \mathrm{final}$ gastric lipase concentration of $17 \mu \mathrm{g} / \mathrm{ml}$ in the mixture of milk and SGF, which corresponds to gastric lipase concentration in gastric contents at half gastric empting [REF]. . During the gastric phase the $\mathrm{pH}$ was kept constant at 5.5 by addition of $\mathrm{HCL}$ and $\mathrm{NaOH}$. At $-2,15$, and 29 minutes samples were taken for analysis. After 30 minutes, $25.2 \mathrm{ml}$ of simulated intestinal fluid was added to represent the ratio of meal to intestinal fluid observed in vivo. ${ }^{29}$ Indeed, a 1.7 dilution factor is observed at half gastric emptying. To represent human pancreatic juice and bile, porcine pancreatic extract (PPE or pancreatin; 8xUSP, Sigma-Aldrich, st Louis, USA) and bovine bile salts (Sigma-Aldrich, st Louis, USA) were mixed and dissolved in $10 \mathrm{mM}$ Tris buffer, $150 \mathrm{mM} \mathrm{NaCl}, \mathrm{pH}$ 6.0. The intestinal phase continued for 60 minutes, so the total digestion experiment lasted 90 minutes. During the intestinal phase the $\mathrm{pH}$ was kept at 6.25 by addition of $\mathrm{NaOH}$.. Samples were taken for analysis at 5, 10, 15, 30 and 60 minutes in the intestinal phase. Enzymes in the samples were inactivated either by heat treatment ( 5 minutes at $72^{\circ} \mathrm{C}$ ) or acidification (addition of $200 \mu \mathrm{l} 0.1 \mathrm{M} \mathrm{HCl}$ ), both well established method to inactivate lipases.Samples were stored at $-80^{\circ} \mathrm{C}$ for further analysis. The simulated gastric and intestinal fluids were made fresh before each experiment, and were 
stored on ice until use. Digestion of the IFs was performed in triplicate. The four human milk samples were digested in independent experiments.

\section{Release of individual fatty acids}

Release of individual FFAs was analysed by the ethyl chloroformate free fatty acid (ECF-FFA) method of Amer et al.$^{30}$ Deuterated internal standards of all FFAs (C4-C18:1) were added to samples and standards. This was followed by in solution derivatisation using a two-step procedure. First $1000 \mu \mathrm{L}$ of the digested samples were mixed with $200 \mu \mathrm{L}$ of ECF. The pH was adjusted to neutral pH with $100 \mu \mathrm{L} 7 \mathrm{M} \mathrm{NaOH}$, followed by a second addition of $200 \mu \mathrm{L}$ of ECF for neutral pH derivatisation. Subsequently, free fatty acids derivatives were extracted with $1000 \mu \mathrm{L}$ chloroform. $1 \mu \mathrm{L}$ aliquots were injected in a splitless mode into an Agilent Technologies 7890A gas chromatography system coupled to an Agilent Technologies 5975c inert MSD quadrupole mass spectrometer (Agilent Technologies, Waghaeusel, Germany). An HP-5MS capillary column coated with polyimide $(60 \mathrm{~m}, 250 \mathrm{~mm}$ i.d., $0.25 \mathrm{~mm}$ film thickness; Agilent Technologies) was used to separate the ECF-derivatised FFAs. The initial temperature of the oven was held at $80^{\circ} \mathrm{C}$ for $2 \mathrm{~min}$, ramped to $140{ }^{\circ} \mathrm{C}$ at a rate of $10^{\circ} \mathrm{C} / \mathrm{min}$, to $240^{\circ} \mathrm{C}$ at a rate of $4{ }^{\circ} \mathrm{C} / \mathrm{min}$, to $280^{\circ} \mathrm{C}$ at a rate of $10^{\circ} \mathrm{C} / \mathrm{min}$, and then held at $280^{\circ} \mathrm{C}$ for $3 \mathrm{~min}$. $\mathrm{A}$ constant flow rate of $1 \mathrm{ml} / \mathrm{min}$ with helium as carrier was applied. The temperatures of the ion source and injector were 230 and $260^{\circ} \mathrm{C}$, respectively. The mass spectral analysis was performed in selected ion monitoring according to the ions determined by the use of a standard for each compound with a quadruple temperature of $150^{\circ} \mathrm{C}$ and a fragmentation voltage of $70 \mathrm{eV}$ with a solvent delay of $6.50 \mathrm{~min}$. Concentration of individual FFAs was quantified using an external calibration curve including deuterated internal standards. Deuterated C18:2 was used as internal standard for all unsaturated C18s. 
Analysis of residual triacylglycerol

To analyse the residual TAG concentration upon digestion, lipids were extracted by mixing $0.5 \mathrm{ml}$ of digestion sample with $125 \mu \mathrm{L}$ methanol, adding $1.25 \mathrm{ml}$ ethyl acetate, mixing and centrifuging for 10 minutes at $3000 \mathrm{rpm}$ at $5^{\circ} \mathrm{C}$ (Hermile Labortechnik Z383K, Wehingen, Germany). The ethyl acetate top layer was removed and stored. This procedure was repeated by re-extracting the sample with $1.25 \mathrm{ml}$ ethyl acetate and centrifugation, after which the ethyl acetate layer was separated and pooled with the first one, and stored at $4{ }^{\circ} \mathrm{C}$ until further analysis. Duplicate extractions were performed for all samples. Gas chromatography coupled to flame ionization detection (GD-FID, Agilent 6990N, Amstelveen, the Netherlands) was used to analyse the TAG concentrations. Using an injector (Gerstel CIS, Mülheim an der Ruhr, Germany), the samples were injected at an initial temperature of $100^{\circ} \mathrm{C}$ and a split ratio of 20:1. A ZB-5HT capillary column $(30 \mathrm{~m}, 250 \mu \mathrm{m}$ i.d., $0.1 \mathrm{~mm}$ film thickness; Phenomenex, Torrance, USA) was used to separate TAGs. The flame-ionization detector (FID) was set to $400^{\circ} \mathrm{C}$. Chromatograms of each sample were obtained and analysed using the Enhanced Data Analysis software from Agilent (Amstelveen, the Netherlands). The values at $\mathrm{t}=0$ were set to $100 \%$ to allow comparison of the different samples. All used chemicals were of analytical standard.

\section{Statistics}

For all parameters, the mean and SD of the three replicate experiments were calculated for both IFs. The results of the individual fourhuman milk digestion experiments were combined and a mean and SD were calculated for all parameters. The data was compared via one-way ANOVA analysis followed by a Bonferonni posthoc test, or Student's t-test when only data of 
202 human milk and IF2 was available. GraphPad Prism (version 5.04 for Windows, GraphPad 203 Software, San Diego California USA) was used.

204 Table 1: Initial fatty acid composition of the infant formula products and human milk samples (in \% of total FAMEs).

\begin{tabular}{|c|c|c|c|c|c|c|c|}
\hline & & & & Human & Human & Human & Human \\
\hline & Fatty acid & IF1 & IF2 & milk-1 & milk-2 & milk-3 & milk-4 \\
\hline SCFA & $\mathrm{C} 4: 0$ & $<0.1$ & 2.6 & $<0.1$ & ND & $<0.1$ & $<0.1$ \\
\hline \multirow[t]{5}{*}{ MCFA } & C6:0 & $<0.1$ & 1.6 & $<0.1$ & ND & $<0.1$ & $<0.1$ \\
\hline & C8:0 & 0.6 & 1.2 & $<0.1$ & $<0.1$ & 0.2 & 0.3 \\
\hline & C10:0 & 0.5 & 2.1 & 0.9 & 0.7 & 1.6 & 1.6 \\
\hline & C11:0 & $<0.1$ & 0.3 & $<0.1$ & $<0.1$ & $<0.1$ & $<0.1$ \\
\hline & C12:0 & 7.0 & 4.3 & 3.8 & 3.1 & 7.8 & 5.6 \\
\hline \multirow[t]{3}{*}{ LCFA } & C14:0 & 3.0 & 8.2 & 6.1 & 6.7 & 10.0 & 5.9 \\
\hline & C15:0 & $<0.1$ & 0.7 & 0.5 & 0.6 & 0.4 & 0.3 \\
\hline & C16:0 & 24.7 & 22.8 & 30.0 & 28.3 & 21.0 & 18.4 \\
\hline & C18:0 & 3.1 & 7.1 & 8.1 & 9.4 & 6.6 & 4.7 \\
\hline & C18:1 n-9cis & 25.4 & 25.9 & 30.3 & 29.8 & 32.2 & 30.8 \\
\hline & C18:2 n-6 & 12.9 & 12.0 & 10.5 & 10.0 & 10.3 & 20.6 \\
\hline & C18:3 n-3 & 1.8 & 1.4 & 0.8 & 0.8 & 0.8 & 1.6 \\
\hline & Total SCFA & $<0.1$ & 2.6 & $<0.1$ & ND & $<0.1$ & $<0.1$ \\
\hline & Total MCFA & 1.3 & 5.2 & 1.2 & 0.9 & 2.0 & 2.1 \\
\hline
\end{tabular}




$\begin{array}{lcccccc}\text { Total LCFA } & 78.0 & 82.4 & 90.1 & 88.7 & 89.1 & 87.9 \\ \text { Total SFA } & 39.3 & 50.9 & 49.8 & 49.0 & 47.9 & 37.1 \\ \text { Total MUFA } & 25.4 & 25.9 & 30.3 & 29.8 & 32.2 & 30.8 \\ \text { Total PUFA } & 14.7 & 13.4 & 11.3 & 10.8 & 11.1 & 22.2\end{array}$

\section{Results}

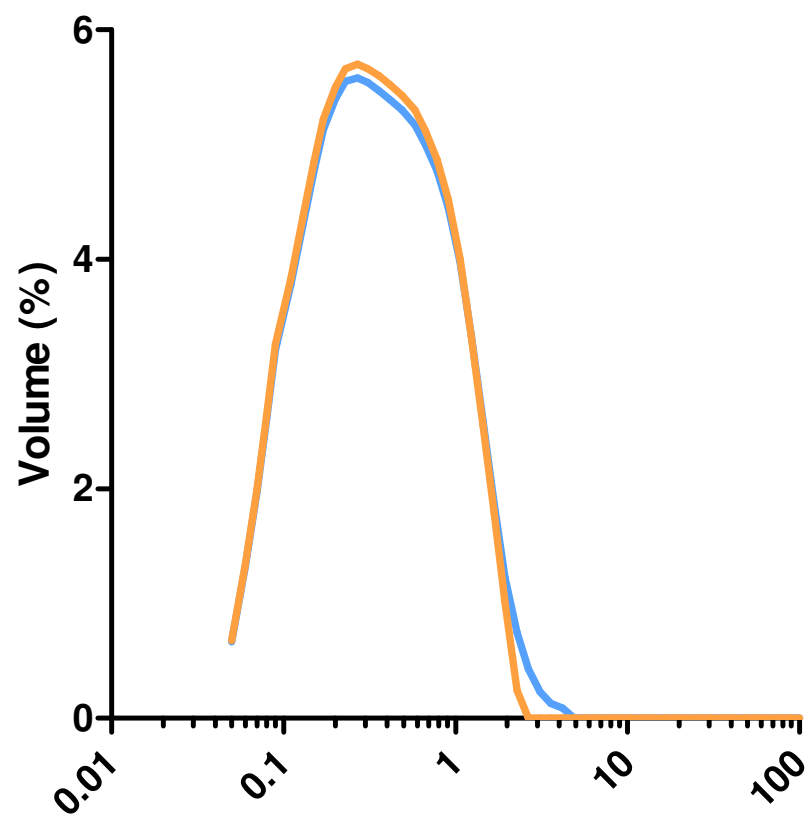

\section{Size $(\mu \mathrm{m})$} concentrations of different time points of the in vitro digestion. The decrease in TAGs is

Figure 1: The particle size distribution of the infant formulas (IF) tested in these digestion experiments. the blue line represents IF1, and the orange line represents IF2

The particle size distribution of the IFs is shown in Figure 1. The modal diameter of both IFs is $0.27 \mu \mathrm{m}$.

Lipolysis of the different milk products was studied by analysing the residual TAG and FFA shown in Figure 1A. In the gastric phase no significant difference between the IFs and human 
milk was found $(p=0.18)$.. At the end of the gastric phase, 24 to $36 \%$ of initial TAG molecules had already been hydrolysed. At the end of the duodenal phase more TAGs remained intact in human milk (8.9\%) compared to IF1 (2.9\%) ( $p=0.02)$. The percentage of remaining TAGs inIF2 (4.4\%) was not different from either human milk or IF-1 ( $p>0.05)$. Figure 1B shows the release of FFA. The human milk samples showed less release of FFAs during the gastric phase compared to IF1 and IF2 ( $2.0 \pm 0.2 \%$ vs $5.1 \pm 0.2 \%$ and $4.7 \pm 0.1 \%$ respectively, $p<0.01)$. As percentage of FFA released after the total digestion, from human milk about $4 \%$ was released during the gastric phase, for IF1 this was about $10 \%$ and for IF2 about $11 \%$ of FFA were released in the gastric phase. Except for 45 minutes in the digestion $(p<0.01)$, no differences were found in FFA release between the IFs compared to the human milk samples during the duodenal phase. However, the comparison of IF1 and IF2 did show some differences. Compared to IF2, IF1 showed a higher release of FFAs at time points 35,40 and $45(p=0.03, p<0.01$, and $p<0.01$ respectively) during the digestion, i.e. it was hydrolysed at a faster rate. However, the total release of FAs at the end of the digestion, as percentage of initial composition, was found to be similar for the different samples $(52.3 \pm 2.4 \%, 42.2 \pm$ $1.4 \%$, and $52.3 \pm 4.5 \%$ for IF1, IF2 and human milk respectively, $p=0.14$ ). 
A

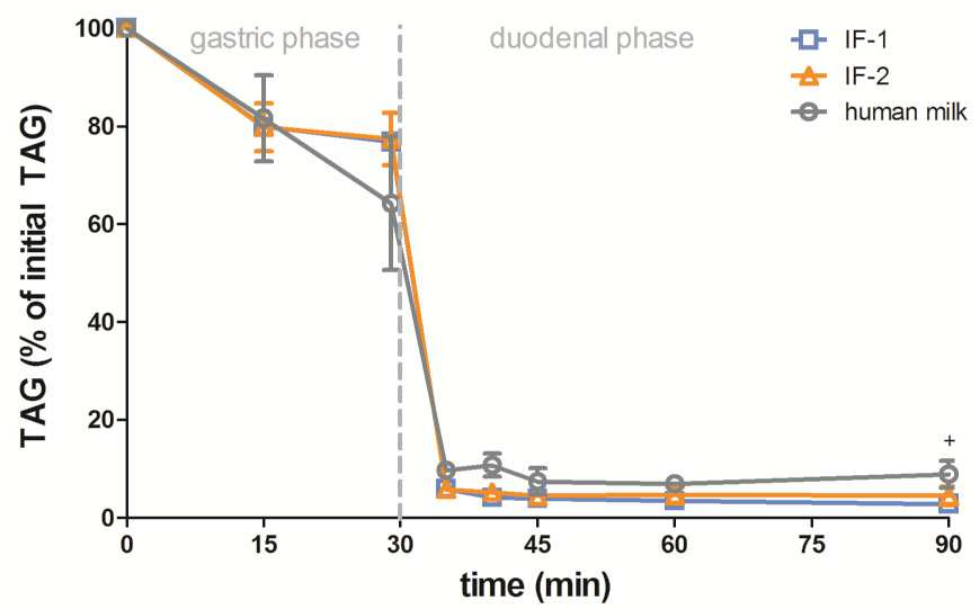

B

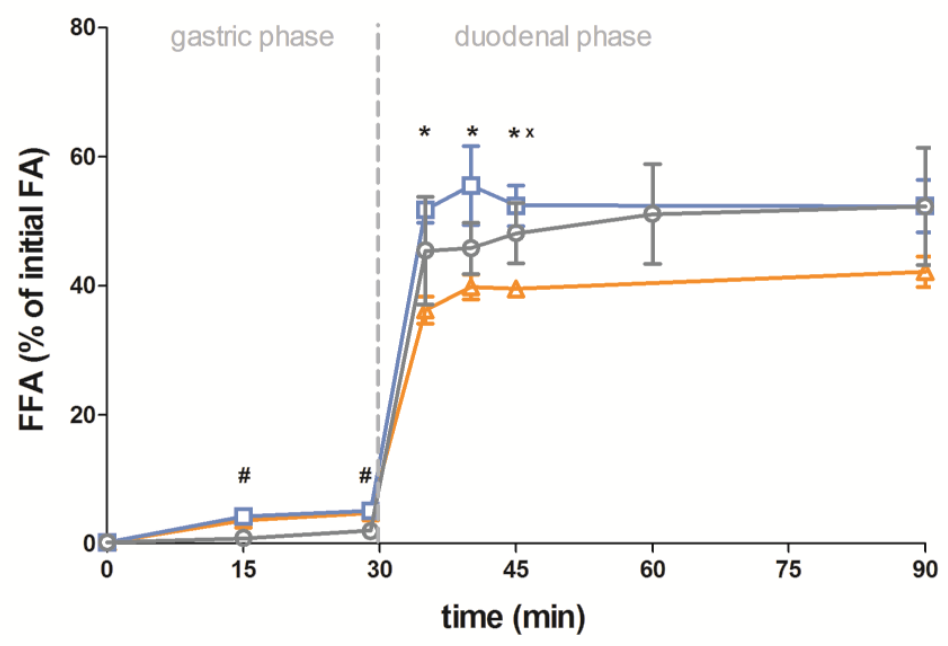

Figure 1: The lipolysis of infant formulas and human milk (mean \pm SD). A: Decrease of triacylglycerols (TAGs) during in vitro digestion in percentage of total TAGs initially present (mean \pm SD). B: Percentage of free fatty acids (FFA) in percentage of total esterified fatty acids (FA) in initial TAGs, during in vitro digestion (mean \pm SD). The vertical striped line indicates the start of the duodenal phase following the gastric phase. The grey line $(\circ)$ represents the average of the human milk samples, the blue line $(\square)$ represents IF1, and the orange line $(\Delta)$ represents IF2. ${ }^{*}$ Significant difference between infants formulas, ${ }^{\#}$ significant difference between both IFs and human milk, ${ }^{+}$significant difference between IF1 and human milk, ${ }^{x}$ significant difference between IF2 and human milk $(p<0.05)$, separate time points were compared with one-way ANOVA, followed by Bonferroni posthoc test. 
released as percentages of total FFAs after the gastric phase $(A)$ and after the duodenal phase (B). During gastric lipolysis MCFA were the main FAs released, followed by palmitic acid (C16:0) and oleic acid (C18:1) (Figure 2A). The digestion of IF2 was distinctly marked by the release of C4:0 originating from bovine milk. The long-chain unsaturated fatty acids (LCUFA) C18:1 and C18:2 from human milk were released at a higher level, whereas for the IFs the percentage released of these fatty acids was much lower. During duodenal lipolysis, the main FAs released were LCFA (Figure 2B). Lipolysis of human milk resulted in higher levels of unsaturated fatty acids (C18:1 and C18:2) compared to the IFs. The profile of FFAs released from IF2 was still marked by a significant level (9.8\%) of C4:0, although this was not found for IF1 and human milk. Furthermore, a higher percentage of all MCFA, except C12:0, was found after lipolysis of IF2. 

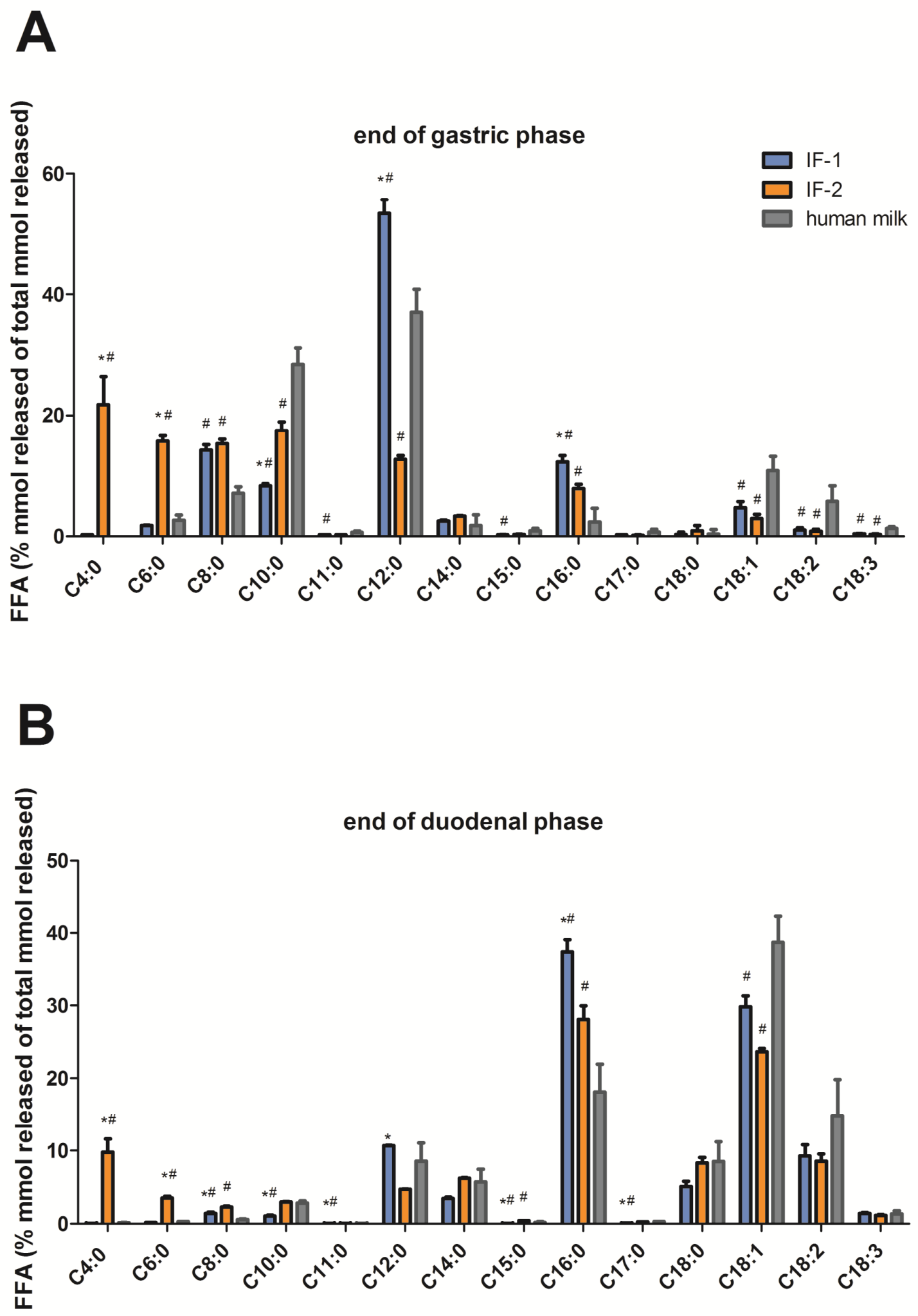

Figure 2: Free fatty acid profile at the end of in vitro gastric digestion (A) and duodenal digestion (B) of IF1 (blue bar), IF2 (orange bar), and human milk (grey bar) (mean \pm SD). ${ }^{*}$ significant difference between IFs, \# significant difference 
Since LCSFA are able to form complexes with calcium, the release of the sum of LCSFA and the most prominent LCSFA, palmitic acid, were compared between the IFs and human milk after digestion (end of duodenal phase). Free palmitic acid was less represented after digestion of human milk ( $18.2 \pm 3.8 \%$ of the FFAs) compared to digestion of IF1 (37.4 $\pm 1.6 \%$; $p<0.001)$ and IF2 $(28.0 \pm 1.9 \% ; p<0.001)$ (Figure $3 \mathrm{~A})$. Of the initial palmitic acid present in TAGS from IFs and human milk, the lowest percentage of palmitic acid (31.8 $\pm 6.0 \%)$ was released from human milk (Figure 3B), while $57.2 \pm 6.9 \%$ and $46.0 \pm 5.6 \%$ respectively was released from IF1 and IF2 ( $p<0.01)$. The total release of LCSFA, as percentage of FFA released (Figure 3C) or as percentage of LCSFA initially present in the IF and human milk TAGs (Figure 3D), was lower in the human milk samples compared to IF1. IF2 did not significantly differ from human milk or from IF1.

A

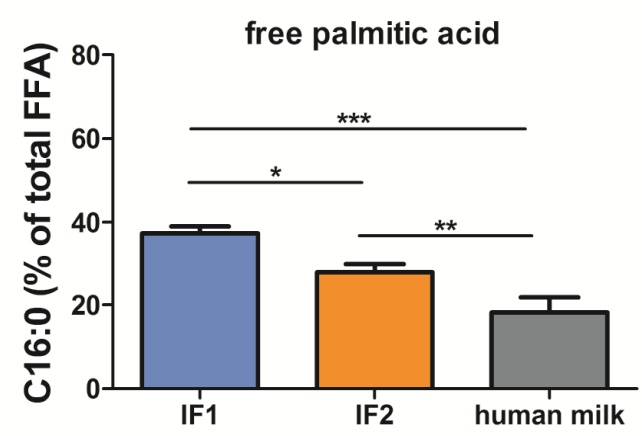

C

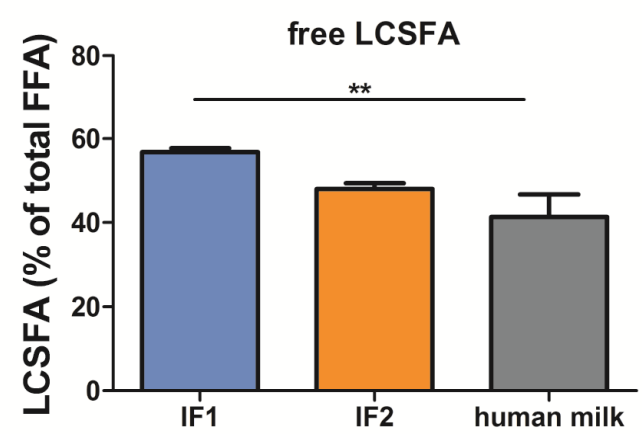

B

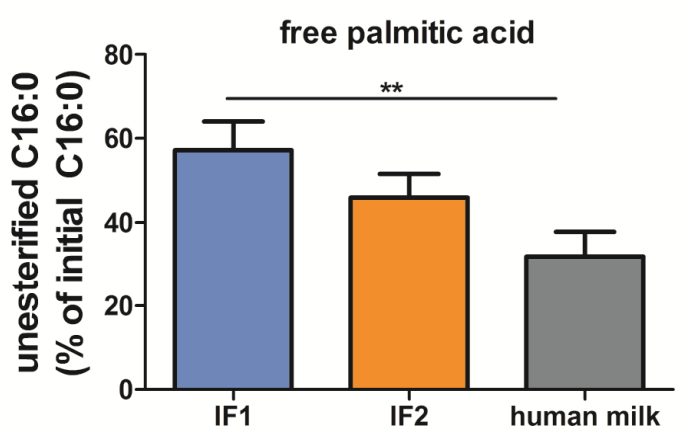

D

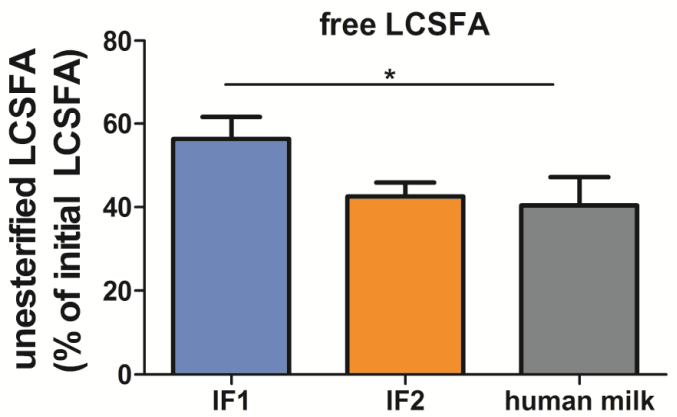


\% of total FFA released upon digestion; D) total free LCSFA expressed as \% of initial amount of total LCSFA in IFs and human milk. IF1, blue bar; IF2, orange bar; human milk, grey bar. Data are (mean \pm SD), and were analysed using one-way ANOVA, and Bonferroni posthoc test, $* \mathrm{p}<0.05,{ }^{* *} \mathrm{p}<0.01, * * * \mathrm{p}<0.001$

Next, the release of individual FAs in time was examined. Figure 4 shows the release of FAs as a percentage of their initial concentration in the IFs and human milk. Table 2 shows the corresponding mean percentages $( \pm S E M)$ of the individual fatty acids released at the end of digestion (90 $\mathrm{min})$ as well as during gastric phase (0-30 $\mathrm{min})$ and duodenal phase (30-90 $\mathrm{min})$ separately. The SCFA, C4:0, which is present in the IF with bovine milk fat (IF2) and found at very low levels in human milk, was partly released in the gastric phase for IF2 (14\%), whereas for human milk no free butyric acid could be detected (Figure 4A, Table 2). The release of C4:0 mainly took place in the duodenal phase, and total release was higher for IF2 compared to human milk (respectively $55 \%$ and $23 \%, p=0.01$ ). The release of $\mathrm{C} 6: 0$ was highest from human milk ( $p=0.02)$, and showed different patterns between the IFs and human milk (Figure 4B, Table 2). For IF1 C6:0 was primarily released in the gastric phase. For IF2, the release in the gastric and duodenal phase was comparable (respectively $25 \%$ and $21 \%$ ). For human milk the release of $\mathrm{C6:0}$ in the duodenal phase was higher compared to the gastric phase (respectively $40 \%$ vs $20 \%$ ). The release of the MCFA C $8: 0$ and C10:0 was similar in the gastric phase and after total digestion for the IFs and human milk $(p=0.38, p=0.13$ and, $p=0 . .06, p=0.11$ respectively). However, in the duodenal phase the release of $\mathrm{C} 8: 0$ and $\mathrm{C} 10: 9$ were higher compared to the IFs ( $p<0.01$ and $p<0.01$ respectively). (Figure 4C-D, Table 2). All of the LCFA, both saturated and unsaturated, were mainly released in the duodenal phase (Figure 4G-M, Table 2). An exception is C12:0, lauric acid, which was also partly released in the gastric phase (Figure 4F, Table 2). The release of C12:0 after total digestion was similar for both IFs and human milk $(p=0.33)$. However, during the gastric phase the release was 
highest for IF1 $(p<0.01)$, while during the duodenal phase the release was higher for human milk compared to the IFs ( $p<0.01)$. From the other LCSFA, except for C15:0, the release from human milk is or tends to be lower compared to IF1 (Table 2). The release of LCUFA after total digestion was higher from human milk compared to the IFs (Table 2) 

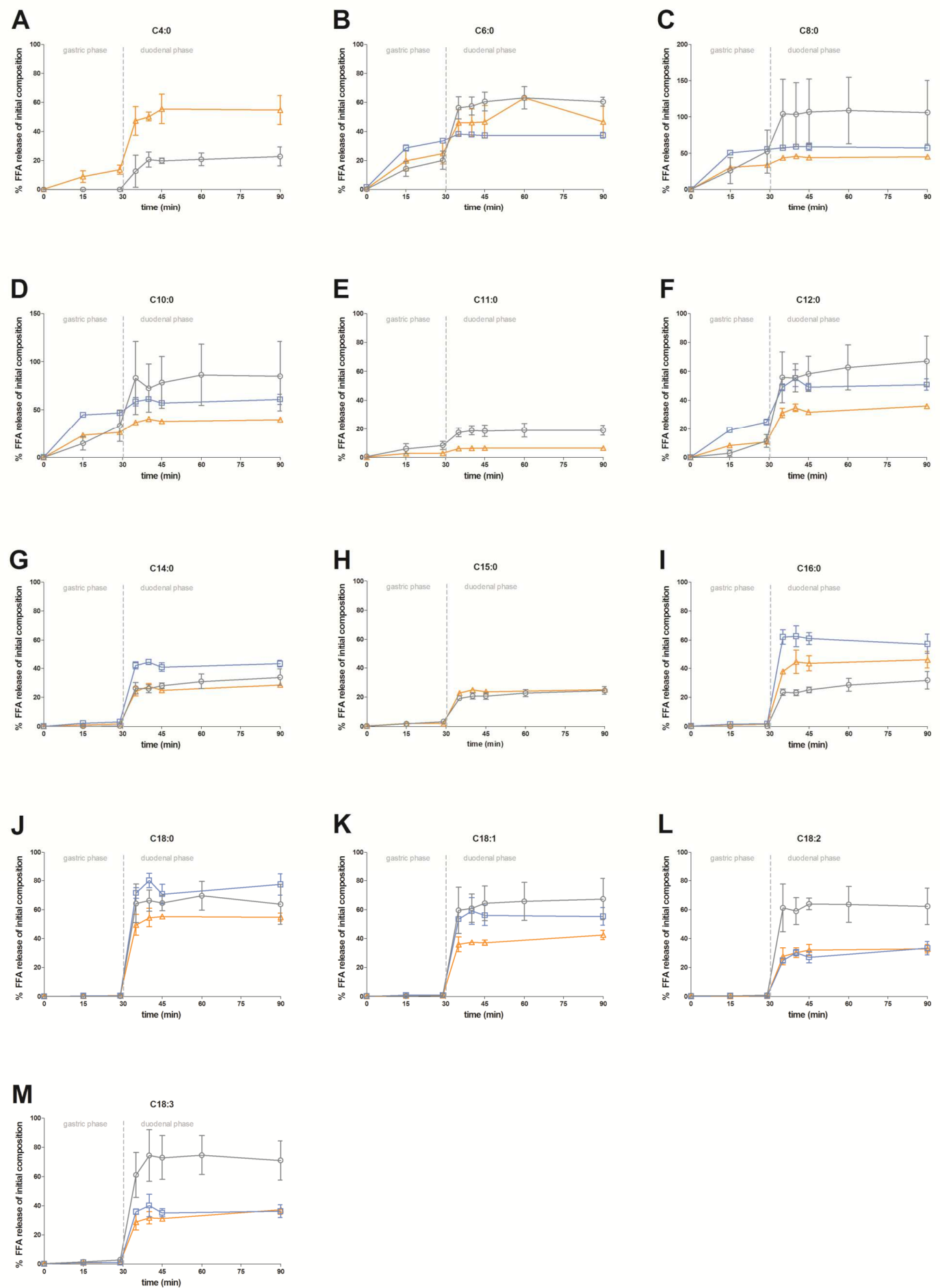

Figure 4: Release of individual fatty acids during in vitro digestion, expressed as percentage of their initial FA content present in IFs and human milk (mean \pm SD); A) C4:0, B) C6:0, C) C8:0, D) C10:0, E) C11:0, F) C12:0, G) C14:0, H) C15:0, I) C16:0, J) C18:0, K) C18:1, L) C18:2, M) C18:3. The vertical striped line indicates the start of the duodenal phase following the gastric phase. The grey line $(\circ)$ represents human milk, the blue line $(\square)$ represents IF1, and the orange line $(\Delta)$ represents IF2. 
Table 2: Release of the individual fatty acids, as percentage of their initial FA content present in IFs and human milk (mean \pm SEM) upon digestion of IF1, IF2 and human milk. P-values

\begin{tabular}{|c|c|c|c|c|c|c|c|c|c|c|c|c|}
\hline \multirow[b]{2}{*}{ Fatty acid (\%) } & \multicolumn{4}{|c|}{ Gastric phase } & \multicolumn{4}{|c|}{ Duodenal phase } & \multicolumn{4}{|c|}{ Total digestion } \\
\hline & IF1 & IF2 & human milk & $p$-value & IF1 & IF-2 & Human milk & $p$-value & IF1 & IF2 & human milk & $p$-value \\
\hline $\mathrm{C} 4: 0$ & nd & $13.7 \pm 1.8^{\mathrm{a}}$ & $0.0 \pm 0.0^{b}$ & $<0.01$ & nd & $41.1 \pm 7.6$ & $22.7 \pm 3.7$ & 0.10 & nd & $54.7 \pm 5.78^{a}$ & $22.7 \pm 3.7^{b}$ & 0.01 \\
\hline $\mathrm{C6}: 0$ & $33.5 \pm 0.71^{b}$ & $24.9 \pm 2.4^{\mathrm{a}}$ & $20.1 \pm 3.7^{a}$ & 0.07 & $3.9 \pm 0.9^{a}$ & $20.7 \pm 1.5^{b}$ & $40.9 \pm 3.1^{c}$ & $<0.01$ & $37.4 \pm 1.1^{\mathrm{a}}$ & $46.6 \pm 3.6^{\mathrm{a}, \mathrm{b}}$ & $60.5 \pm 1.8^{b}$ & 0.02 \\
\hline C8:0 & $55.5 \pm 0.76$ & $34.1 \pm 0.4$ & $52.4 \pm 14.8$ & 0.38 & $1.8 \pm 0.8^{a}$ & $11.3 \pm 0.7^{\mathrm{a}}$ & $53.8 \pm 15.8^{b}$ & $<0.01$ & $57.3 \pm 1.1$ & $45.4 \pm 0.0$ & $106.2 \pm 22.0$ & 0.06 \\
\hline $\mathrm{C} 10: 0$ & $46.8 \pm 0.59$ & $26.5 \pm 1.0$ & $33.4 \pm 8.2$ & 0.13 & $14.1 \pm 4.5^{\mathrm{a}}$ & $13.5 \pm 2.7^{\mathrm{a}}$ & $51.6 \pm 19.6^{b}$ & $<0.01$ & $60.9 \pm 3.0$ & $40.0 \pm 0.9$ & $85.0 \pm 18.0$ & 0.11 \\
\hline C11:0 & nd & $3.0 \pm 0.1^{a}$ & $8.5 \pm 1.4^{b}$ & 0.02 & nd & $3.6 \pm 0.3^{\mathrm{a}}$ & $10.4 \pm 2.1^{b}$ & $<0.01$ & nd & $6.6 \pm 0.2^{a}$ & $19.0 \pm 1.8^{b}$ & $<0.01$ \\
\hline C12:0 & $24.9 \pm 1.20^{\mathrm{a}}$ & $10.9 \pm 0.2^{b}$ & $11.6 \pm 2.2^{b}$ & $<0.01$ & $26.0 \pm 3.9^{\mathrm{a}}$ & $25.1 \pm 1.5^{\mathrm{a}}$ & $55.5 \pm 12.9^{b}$ & $<0.01$ & $50.9 \pm 2.3$ & $36.1 \pm 0.9$ & $67.1 \pm 8.7$ & 0.33 \\
\hline C14:0 & $3.1 \pm 0.25^{\mathrm{a}}$ & $1.71 \pm 0.0^{b}$ & $0.4 \pm 0.1^{c}$ & $<0.01$ & $40.2 \pm 2.0^{a}$ & $26.9 \pm 1.4^{b}$ & $33.5 \pm 5.7^{a, b}$ & 0.01 & $43.3 \pm 1.3^{a}$ & $28.6 \pm 0.8^{b}$ & $33.9 \pm 2.9^{\mathrm{a}, \mathrm{b}}$ & $<0.01$ \\
\hline $\mathrm{C} 15: 0$ & nd & $2.1 \pm 0.2$ & $3.3 \pm 0.9$ & 0.35 & nd & $23.1 \pm 1.0$ & $18.7 \pm 4.5$ & 0.16 & nd & $25.2 \pm 0.6$ & $24.6 \pm 2.6$ & 0.83 \\
\hline C16:0 & $1.8 \pm 0.13^{a}$ & $1.5 \pm 0.1^{\mathrm{a}}$ & $0.2 \pm 0.1^{b}$ & $<0.01$ & $55.4 \pm 6.7^{\mathrm{a}}$ & $44.5 \pm 5.7^{\mathrm{a}, \mathrm{b}}$ & $31.7 \pm 6.0^{b}$ & $<0.01$ & $57.2 \pm 4.0^{\mathrm{a}}$ & $46.0 \pm 3.2^{\mathrm{a}, \mathrm{b}}$ & $31.8 \pm 3.0^{b}$ & $<0.01$ \\
\hline C18:0 & $0.5 \pm 0.33$ & $0.7 \pm 0.4$ & $0.2 \pm 0.2$ & 0.51 & $76.9 \pm 7.7$ & $54.1 \pm 2.7$ & $63.5 \pm 13.6$ & 0.07 & $77.4 \pm 4.2$ & $54.8 \pm 1.6$ & $63.7 \pm 6.9$ & 0.07 \\
\hline C18:1 & $0.9 \pm 0.11$ & $0.6 \pm 0.1$ & $0.7 \pm 0.1$ & 0.40 & $54.4 \pm 5.8^{\mathrm{a}, \mathrm{b}}$ & $41.9 \pm 3.2^{\mathrm{a}}$ & $66.6 \pm 14.0^{b}$ & 0.04 & $55.3 \pm 3.5^{\mathrm{a}, \mathrm{b}}$ & $42.5 \pm 1.8^{b}$ & $67.4 \pm 7.1^{\mathrm{a}}$ & 0.04 \\
\hline C18:2 & $0.4 \pm 0.07^{\mathrm{a}}$ & $0.4 \pm 0.1^{\mathrm{a}}$ & $1.0 \pm 0.2^{b}$ & 0.02 & $33.0 \pm 4.6^{\mathrm{a}}$ & $32.6 \pm 3.0^{a}$ & $61.1 \pm 12.4^{b}$ & $<0.01$ & $33.4 \pm 2.6^{\mathrm{a}}$ & $32.9 \pm 1.7^{\mathrm{a}}$ & $62.3 \pm 6.3^{b}$ & $<0.01$ \\
\hline $\mathrm{C} 18: 3$ & $1.0 \pm 0.16^{a}$ & $1.2 \pm 0.2^{a}$ & $2.9 \pm 0.5^{b}$ & 0.02 & $35.2 \pm 4.1^{\mathrm{a}}$ & $36.1 \pm 3.1^{\mathrm{a}}$ & $68.16 \pm 12.6^{b}$ & $<0.01$ & $36.2 \pm 2.5^{a}$ & $37.4 \pm 1.9^{a}$ & $71.1 \pm 6.7^{b}$ & $<0.01$ \\
\hline
\end{tabular}




\section{Discussion}

This is the first in vitro study to investigate the difference in lipolysis between an IF containing bovine milk fat and an IF with vegetable fats only, and to compare this with the lipolysis of human milk. Using a two-step in vitro infant digestion model, which consisted of a gastric and a duodenal phase, no differences in total FA release at the end of digestion between the different IFs and human milk were found in these experiments. Therefore, this study showed that addition of bovine milk fat to IF did not results in a different total extent of lipolysis compared to an IF containing vegetable fats only or human milk.

In vitro lipolysis

In this study we tried to mimic the digestion as occurring in infants. Therefore, the gastric $\mathrm{pH}$ was set to infant levels, which is higher compared to that of adults. ${ }^{31}$ Gastric and duodenal $\mathrm{pH}$ values were chosen to correspond to conditions existing in the stomach and duodenum at half gastric emptying time of a meal. ${ }^{29}$ The gastric lipase that is used has characteristics similar to human gastric lipase, including stereo-preference and $\mathrm{pH}$-activity level. ${ }^{27}$ In addition, the duration of digestion that was used in this model was quite short compared to that of other in vitro digestion models. Whereas some other models use a gastric phase of several hours ${ }^{32-34}$, the gastric phase of the current model lasted only 30 minutes. However, this is in line with the findings of Roman et al, who showed that the gastric emptying time of an infant is approximately 30 minutes. ${ }^{6}$ Moreover, the gastric lipolysis levels reached after 30 min under these conditions of $\mathrm{pH}$ and gastric lipase concentration are equivalent to those recorded in vivo during the whole gastric digestion period. ${ }^{29,35}$ Further improvement of the model could involve stepwise transfer of product fractions to the duodenal phase, mimicking the process of gastric emptying, and gradual addition of digestive enzymes. These two 
effects potentially negate each other. In view of the rapid lipolysis that is observed, these alterations are unlikely to affect the currently observed outcomes.

\section{SCFA analysis}

Previous studies investigating the in vitro lipolysis of bovine milk, human milk and IFs only determined the release of FA with a carbon number equal to or higher than six. ${ }^{36-41}$ The extraction of C4:0 and its quantification are notoriously difficult due to its partial solubility in water, volatility and poor detection with various analytical techniques. Therefore, the level of C4:0 released from milk TAGs are often not determined during both in vitro and in vivo digestion studies. However, since $\mathrm{C} 4: 0$ is present in relatively high levels in bovine milk fat, in this study it was essential to determine the release of this FA as well. Therefore, an insolution derivatization approach was used allowing all FFA to be extracted after an conversion to ethyl esters in the investigated matrix. This method thus prevents loss and allows for quantitative measurements. ${ }^{30}$ Therefore, the total FFA profile, including C4:0, could be studied, which normally fail to be investigated due to their water solubility. The insolution derivatization approach allowed us to show a full picture of the specificity of gastric lipase and gastric lipolysis, concerning all FAs in the investigated matrices.

\section{Gastric lipolysis}

The present in vitro digestion experiments showed that during the gastric phase, only a small percentage of total FAs were released. For the IFs about $10 \%$ of total FFAs were released in the gastric phase, which is in line with previous findings. ${ }^{25,31,34}$ The gastric lipolysis of human milk samples was around twofold lower, with about $4 \%$ of total FFA release. This may be due to the presence of the human milk fat globule membrane in fresh human milk, which is less accessible to lipases than the globules in IF. ${ }^{42,43}$. Another explanation might be the larger 
lipid-water interface exposed to the lipases ${ }^{44}$, since the IFs used in these experiments have a modal diameter of $0.3 \mu \mathrm{m}$, while human milk is known to have a larger modal diameter, around $4 \mu \mathrm{m} .{ }^{45}$. Since no significant difference was found for the clearance of TAGs between human milk and IFs in the gastric phase, the differences in FFA release and lipolysis levels can easily be explained by further hydrolysis of DAGs generated from TAGs of IFs. However, this was not studied here and thus remains speculative.

Since samples were taken at different time points during the in vitro digestion it was possible to study the time-dependent release of the individual fatty acids. During gastric lipolysis mainly MCFA and part of C4:0 (for IF2 only) were released, with only some LCSFA. Most of the released LCSFA was C12:0. In this study we defined C12:0 as a LCFA since it has the ability to form calcium soaps like other LCSFA. ${ }^{20}$ However, lauric acid is more water soluble than $\mathrm{FA} \geq \mathrm{C} 14^{46}$, and can partly be directly absorbed into the portal vein. ${ }^{47}$ Therefore it is sometimes considered as being a MCFA. ${ }^{48}$ This study shows that the $\mathrm{C} 12: 0$ release in time are in line with MCFA, and therefore the results support the categorization of $\mathrm{C} 12: 0$ as a MCFA. The preferential release of the short and medium chain FA is according to expectation, since it corresponds to the specificity of gastric lipase. ${ }^{4,5}$ For human milk no release of $\mathrm{C} 4: 0$ was found in the gastric phase, however, the levels of $\mathrm{C} 4: 0$ in the human milk samples was very low (Table 1), therefore, the amount of C4:0 released might have been below detection.

\section{Duodenal lipolysis}

In the duodenal phase, lipolysis occurred at a faster rate and reached higher levels. After 10 minutes almost maximum lipolysis was reached for all samples. Thus, the pancreatic extract, containing pancreatic lipase, in combination with bile salt, acted very efficiently. This high 
efficiency may have precluded identification of subtle differences in digestion kinetics. Such differences may possibly have been observed using lower concentrations of lipases.

However, lower lipase concentrations would not have been physiologically relevant for term infants, as the conditions we used were based on in vivo data obtained from term infants. ${ }^{35}$

The release of FA from initial TAGs found in these experiments after the duodenal phase is between 42 and $52 \%$. These values have to be compared with a lipolysis level of $67 \%$ (TAGs totally converted in MAGs and FFAs) that allows full intestinal absorption of lipolysis products. The model used here has been shown to well reproduce the lipolysis levels observed in vivo at the Angle of Treitz, i.e. the end of the duodenum. ${ }^{49}$ It does not allow to observe full lipolysis, but it appears suitable for comparing various type of meals ${ }^{29}$, emulsions ${ }^{50,51}$ and, as shown here, IFs versus milk.

As expected, the FFA profile in the duodenal phase was somewhat different between the different fat blends. In the course of human milk lipolysis, higher levels of unsaturated fatty acids (C18:1 and C18:2) were released, and lower levels of saturated fatty acids, compared to the IFs. This is in line with the starting hypothesis that human milk has its LCUFA mostly placed at the sn-1 and sn-3 positions and LCSFA at the sn-2 position. Whereas both IFs contain similar levels of palmitic acid, less was released in the bovine milk fat containing blend, which is likely due to the higher level of palmitic acid at the sn-2 position in this blend. Palmitic acid, and also the other LCSFA, are known to form insoluble calcium soaps in the intestinal lumen. ${ }^{19,20}$ The formation of calcium soaps is linked to digestive problems, such as constipation and therefore discomfort. ${ }^{19}$ The release of LCSFA from the IF containing bovine milk fat was not different from human milk. Thus, after digestion of IF with bovine milk fat less unesterified palmitic acid is present and the total LCSFA is not different from human 
milk.. Therefore, it is expected that addition of bovine milk fat to IF leads to less calcium soap formation and thereby less gut discomfort.

Not only LCFA were released in the duodenal phase in the course of human milk digestion. Unexpectedly, also part of the MCFA from human milk and part of C4:0, from human milk and IF containing bovine milk fat, were released. Since C4:0 and MCFA are mostly positioned at the sn-1 and sn-3 position of the glycerol backbone, they are thought to be preferentially released by gastric lipase in the stomach. However, gastric lipolysis is rapidly inhibited by $\mathrm{FFA}^{52}$, and therefore some C4:0 and MCFA may have reached the duodenal phase still esterified in TAGs (or DAGs). Gastric lipase can still work in the duodenal phase where its inhibition by lipolysis products, which is observed in gastric conditions ${ }^{53}$, is abolished by bile salts. This has been shown in chronic pancreatitis patients with no pancreatic lipase. ${ }^{54}$ In addition, pancreatic lipase is a 1,3-regioselective lipase that can also preferentially release the FAs esterified to the sn-3 position of the glycerol backbone. The difference in time points of release of MCFA between human milk and IFs may also be explained by differences in TAG composition. It has been shown that the percentage of C8:0 at the sn-2 position is higher in the milk of Chinese mothers compared to IF. ${ }^{23}$ Such positioning of those FAs at the glycerol backbone could have partly protected them from lipolysis in the gastric phase of digestion.

\section{Possible health effects}

The preferential release of C4:0 and mainly MCFA in the gastric phase of digestion is potentially linked with the fact that these FAs can already be absorbed by the gastric cells. ${ }^{55,56}$ When they reach the intestinal lumen they could possibly exert effects on epithelial cells. MCFA are hypothesized to have beneficial effects, like antimicrobial effects. ${ }^{57,58}$ The same holds true for C4:0, butyric acid, which is present in bovine milk fat and in trace 
amounts in human milk. Butyrate, and other SCFA, are largely produced by microbial fermentation in the intestine and are generally considered as important mediators of the beneficial health effect of intestinal microbiota, contribution to epithelial maturation and barrier function. ${ }^{59,60}$ Since microbial fermentation occurs predominantly in the colon, it is of interest that milk and IF have the potential to deliver SCFA to the small intestine. A study performed in piglets showed that consumption of butyrate improved development of the jejunum and ileum crypt depth, villi length and mucosa thickness were increased. ${ }^{61}$ Whether the levels of butyric acid present in human milk and IF containing bovine milk fat contributes to small intestinal maturation and functioning still needs to be determined.

\section{Conclusion}

The addition of bovine milk fat to IF, and thereby changing the triglyceride structure, did not influence the total amount of release of fatty acids in time compared to an IF with vegetable fat only or human milk. However, the profile of the fatty acids that are released was found to be different. More SCFA and MCFA, and less LCSFA, especially palmitic acid, were released from an IF containing a combination of bovine milk fat and vegetable fat compared to an IF containing only vegetable fat. The FFA profile of human milk distinguishes from the IF products by a higher release of MCFA and an even lower release of palmitic acid in the duodenal phase.

\section{Abbreviation (optional)}

FA: fatty acid

FFA: free fatty acid

LCFA: long-chain fatty acid (C12:0>higher) 
LCUFA: long-chain unsaturated fatty acid

SCFA: short-chain fatty acid, (C4:0)

SFA: saturated fatty acid

TAG: triacylglycerol

457

UFA: unsaturated fatty acid

\section{Conflict of interest}

\section{References}

4611 European Commission, 2006.

4622 W. G. Manson and L. T. Weaver, Archives of disease in childhood. Fetal and neonatal edition, 1997, 76, F206-11.

3 S. Lindquist and O. Hernell, Current opinion in clinical nutrition and metabolic care, 5. 20271-6. 

Pediatric Research, 2007, 61, 83-88. Biochemistry, 2003, 67, 1937-1943.

S. Bernbäck, L. Bläckberg and O. Hernell, The Journal of clinical investigation, 1990, 85, 1221-6.

C. Eydoux, S. Spinelli, T. L. Davis, J. R. Walker, A. Seitova, S. Dhe-Paganon, A. De Caro,

C. Cambillau and F. Carrière, Biochemistry, 2008, 47, 9553-9564. Research, 2011, 52, 1949-1956.

K. Johnson, L. Ross, R. Miller, X. Xiao and M. E. Lowe, Pediatric Research, 2013, 74, $127-132$.

E. Abrahamse, M. Minekus, G. A. van Aken, B. van de Heijning, J. Knol, N. Bartke, R. Oozeer, E. M. van der Beek and T. Ludwig, Food digestion, 2012, 3, 63-77. Journal of Pediatrics, 1986, 108, 439-447. of pediatric gastroenterology and nutrition, 2006, 42, 293-9. 
S. M. Innis, Advances in Nutrition: An International Review Journal, 2011, 2, 275-283.

P. T. Quinlan, S. Lockton, J. Irwin and A. L. Lucas, Journal of pediatric gastroenterology and nutrition, 1995, 20, 81-90.

M. Yao, E. L. Lien, M. R. Z. Capeding, M. Fitzgerald, K. Ramanujam, R. Yuhas, R. gastroenterology and nutrition, 2014, 59, 440-8.

21 A. Berger, M. Fleith and G. Crozier, Journal of Pediatric Gastroenterology and Nutrition, 2000, 30, 115-130. Journal, 2016, 42-51.

J. H. J. Hageman, M. Danielsen, A. G. Nieuwenhuizen, A. L. Feitsma and T. K. Dalsgaard, International Dairy Journal, 2019, 92, 37-49. Hernandez and F. Carrière, Food \& Function, 2014, 5, 1409. 
28 F. Carriere, J. A. Barrowman, R. Verger and R. Laugier, Gastroenterology, 1993, 105, 876-888.

F. Carrière, C. Renou, V. Lopez, J. De Caro, F. Ferrato, H. Lengsfeld, A. De Caro, R. Laugier and R. Verger, Gastroenterology, 2000, 119, 949-60.

B. Amer, C. Nebel, H. C. Bertram, G. Mortensen, K. Hermansen and T. K. Dalsgaard, International Dairy Journal, 2013, 32, 199-203.

L. Poquet and T. J. Wooster, Molecular Nutrition \& Food Research, 2016, 60, 18761895.

C. Bourlieu, O. Ménard, A. De La Chevasnerie, L. Sams, F. Rousseau, M.-N. Madec, B.

Robert, A. Deglaire, S. Pezennec, S. Bouhallab, F. Carrière and D. Dupont, Food chemistry, 2015, 182, 224-35.

34 T. T. P. Nguyen, B. Bhandari, J. Cichero and S. Prakash, Food Research International, 2018, 106, 696-705.

35 C. Roman, F. Carriere, P. Villeneuve, M. Pina, V. Millet, U. Simeoni and J. Sarles, Pediatric Research, 2007, 61, 83-88. 
36 M. H. Tunick, D. X. Ren, D. L. Van Hekken, L. Bonnaillie, M. Paul, R. Kwoczak and P. M. Tomasula, Journal of Dairy Science, 2016, 99, 4124-4139.

37 P. J. Sassene, M. Fan $\varnothing$, H. Mu, T. Rades, S. Aquistapace, B. Schmitt, C. Cruz-Hernandez, T. J. Wooster and A. Müllertz, Food \& function, 2016, 7, 3989-3998.

38 S. Gallier, J. Cui, T. D. Olson, S. M. Rutherfurd, A. Ye, P. J. Moughan and H. Singh, Food chemistry, 2013, 141, 3273-81.

39 S. C. de Oliveira, C. Bourlieu, O. Ménard, A. Bellanger, G. Henry, F. Rousseau, E. Dirson, F. Carrière, D. Dupont and A. Deglaire, Food Chemistry, 2016, 211, 171-179.

40 H. Devle, E. K. Ulleberg, C. F. Naess-Andresen, E.-O. Rukke, G. Vegarud and D. Ekeberg, International Dairy Journal, 2014, 36, 6-13.

41 M. A. Islam, H. Devle, I. Comi, E. K. Ulleberg, E.-O. Rukke, G. E. Vegarud and D. Ekeberg, International Dairy Journal, 2017, 65, 14-19.

42 T. T. Le, T. Van de Wiele, T. N. H. Do, G. Debyser, K. Struijs, B. Devreese, K. Dewettinck and J. Van Camp, Journal of Dairy Science, 2012, 95, 2307-2318.

43 C. Garcia, C. Antona, B. Robert, C. Lopez and M. Armand, Food Hydrocolloids, 2014, 35, 494-504.

44 C. Bourlieu, O. Ménard, A. De La Chevasnerie, L. Sams, F. Rousseau, M.-N. Madec, B. Robert, A. Deglaire, S. Pezennec, S. Bouhallab, F. Carrière and D. Dupont, Food Chemistry, 2015, 182, 224-235.

45 M. C. Michalski, V. Briard, F. Michel, F. Tasson and P. Poulain, Journal of dairy science, $2005,88,1927-40$. 
S. D. Nielsen, B. Amer, K. Blaabjerg, T. K. Dalsgaard, R. Jessen, B. Petrat-Melin, M. K. Rasmussen, H. D. Poulsen and J. F. Young, Journal of Agricultural and Food Chemistry, 2017, 65, 281-290.

47 J. P. Perret, Journal of Physiology (Paris), 1980, 76, 159-66.

48 M. F. McCarty and J. J. DiNicolantonio, Open heart, 2016, 3, e000467.

49 T. Bohn, F. Carriere, L. Day, A. Deglaire, L. Egger, D. Freitas, M. Golding, S. Le Feunteun, A. Macierzanka, O. Menard, B. Miralles, A. Moscovici, R. Portmann, I. Recio, D. Rémond, V. Santé-Lhoutelier, T. J. Wooster, U. Lesmes, A. R. Mackie and D. Dupont, Critical Reviews in Food Science and Nutrition, 2017, 1-23.

50 L. Couëdelo, S. Amara, M. Lecomte, E. Meugnier, J. Monteil, L. Fonseca, G. Pineau, M. Cansell, F. Carrière, M. C. Michalski and C. Vaysse, Food \& function, 2015, 6, 1726-35.

51 C. Vors, P. Capolino, C. Guérin, E. Meugnier, S. Pesenti, M.-A. Chauvin, J. Monteil, N. Peretti, M. Cansell, F. Carrière and M.-C. Michalski, Food \& Function, 2012, 3, 537.

52 Y. Pafumi, D. Lairon, P. L. de la Porte, C. Juhel, J. Storch, M. Hamosh and M. Armand, The Journal of biological chemistry, 2002, 277, 28070-9.

53 Y. Pafumi, D. Lairon, P. L. de la Porte, C. Juhel, J. Storch, M. Hamosh and M. Armand, The Journal of biological chemistry, 2002, 277, 28070-9.

54 F. Carrière and R. Laugier, Clinical Gastroenterology and Hepatology, 2005, 3, 715.

55 J. Faber, R. Goldstein, O. Blondheim, H. Stankiewicz, A. Darwashi, J. A. Bar-Maor, A. Gorenstein, A. I. Eidelman and S. Freier, Journal of pediatric gastroenterology and nutrition, 7, 189-95. 

12, 209-215. 139, 1619-25.

57960 H. Liu, J. Wang, T. He, S. Becker, G. Zhang, D. Li and X. Ma, Advances in Nutrition, $2018,9,21-29$.

A. Kotunia, J. Woliński, D. Laubitz, M. Jurkowska, V. Romé, P. Guilloteau and R. Physiological Society, 2004, 55 Suppl 2, 59-68. 